\section{Bacterial contamination of platelet concentrates: pathogen detection and inactivation methods}

\author{
Dana Védy, Daniel Robert, \\ Danielle Gasparini, Giorgia Canellini, \\ Sophie Waldvogel, Jean-Daniel Tissot \\ Service Régional Vaudois de Transfusion \\ Sanguine, Lausanne, Switzerland
}

\begin{abstract}
Whereas the reduction of transfusion related viral transmission has been a priority during the last decade, bacterial infection transmitted by transfusion still remains associated to a high morbidity and mortality, and constitutes the most frequent infectious risk of transfusion. This problem especially concerns platelet concentrates because of their favorable bacterial growth conditions. This review gives an overview of platelet transfusion-related bacterial contamination as well as on the different strategies to reduce this problem by using either bacterial detection or inactivation methods.
\end{abstract}

\section{Introduction}

Reduction of transfusion related viral transmission such as HIV, HBV or HCV has been a priority for blood transfusion services. Implementation of antibody screening followed by nucleic acid amplification techniques (NAT) introduced in blood donor screening during the last decade, have largely contributed to this reduction. ${ }^{1.5}$ Nevertheless, all blood products remain under the threat of emerging blood-transmitted infections (virus, protozoans, helminths, bacteria, prions) ${ }^{6}$ and bacterial transfusion related transmission is still associated to a high morbidity and mortality. ${ }^{1-3,5,7-10}$ Platelets are especially affected by this risk, and septic infections are most commonly associated with platelet transfusion because of the favorable bacterial growth conditions that are: i) room temperature storage allowing the growth of even small bacterial inoculums and, ii) the biological composition of platelet concentrates. ${ }^{3.5,9,11,12}$

The estimated rate of bacterial platelet contamination is about 1/2,000-3,000 units (wholeblood and apheresis-derived platelets) ${ }^{1-3,5}$ and a severe sepsis may be associated with one out of 6 of contaminated platelet units transfused. ${ }^{3}$ The risk of bacterial contamination of platelet concentrates has been estimated to be $50-250$ times higher than the combined risk of HIV, HBV, HCV and HTLV-1/2. ${ }^{9}$ Transfusion related sepsis is often not recognized, and the real clinical and fatal prevalence are probably underestimated. ${ }^{10}$

\section{Platelet transfusion-related bacterial contamination: some data}

In the United States, bacterial contamination is considered, after transfusion errors, as the second most common cause of death related to transfusion. ${ }^{1}$ As mentioned by Holme $e t$ al., the estimated number of patients who received bacterial contaminated platelets per year ranges from 2,000-4,000, resulting in 200600 cases of clinical sepsis, and an estimated 40-533 fatalities. ${ }^{2}$ The death risk in the USA has been estimated at 1/500,000 platelet concentrates. Between 1995 and 2001, the English hemovigilance system reported 21 transfusionrelated bacterial contamination, leading to 6 deaths, in which 5 were attributed to platelet contamination. ${ }^{13}$ In France, Fournier-Wirth et al. reported that the incidence of transfusion related reactions due to bacterial contaminated platelets was about 1/25,000 units that was associated with severe morbidity or even mortality in about 3 cases each year in the period 1999-2003. ${ }^{14}$ The death rate was estimated to be one death per 200,000 distributed platelet concentrates. $^{13}$

\section{Platelet contamination: source and species of bacteria}

Several mechanisms may lead to platelet contamination, the major being contamination by the skin flora at the site of punction., ${ }^{3,7}$ Pathogens are essentially gram positive bacteria like Staphylococcus aureus, coagulase negative Staphylococci, viridans group Streptococci, Bacillus spp., Corynebacteria as well as anaerobic diphteroid gram positive bacilli such as Propionibacterium acnes. ${ }^{3,8,11}$ In 2004, in a review dealing with transfusion-transmitted bacterial infections, Wagner reported that about $56 \%$ of bacteria detected in platelet units implicated in clinical situations of transfusion associated sepsis were aerobic gram-positive bacteria. ${ }^{10}$ However, in the presence of gram negative organisms, the outcome was more frequently fatal $(60 \%)$ when compared with gram positive ones (40\%). The distribution of bacteria found in cases of transfusion related sepsis showed Staphylococcus spp. in $42 \%$ of cases, Escherichia coli in $9 \%$, Bacillus spp. in 9\%, Salmonella spp. in 9\%, Streptococcus spp.
Correspondence: Dana Védy,

Service Régional Vaudois de Transfusion Sanguine, Route de la Corniche 2, CH-1066 Epalinges, Switzerland

E-mail: dana.vedy@mavietonsang.ch

Conflict of interest: none

Received for publication: 13 January 2009

Revision received: 19 March 2009

Accepted for publication: 24 March 2009

This work is licensed under a Creative Commons Attribution 3.0 License (by-nc 3.0)

CC Copyright Dana Védy et al., 2009

Licensee PAGEPress, Italy

Hematology Reviews 2009; 1:e5

doi:10.4081/hr.2009.e5

in $12 \%$, Serratia spp. in $8 \%$, Enterobacter spp. in $7 \%$, and other organisms in $4 \%$. The clinician should be aware that uncommon pathogens might be encountered in platelet preparations. $^{4,15}$

Infrequently, donor bacteremia may be present during blood collection, also leading to platelet contamination. In a large study evaluating the risk of septic platelet transfusion reactions, 23 septic transfusion reactions were observed; 15 out of 23 reactions (62.5\%) were attributed to skin flora contamination, and 8 out of $23(34.8 \%)$ resulted from bacteria, more likely associated to transient donor bacteremia. ${ }^{16}$ Furthermore, the authors also showed that pooled platelet concentrates from buffy coats have a higher bacterial contamination rate compared to apheresis platelets. A total of 32,333 pooled-platelet concentrates and of 134,159 single-donor platelet concentrates were transfused with a rate of septic transfusion reaction of $13 / 32,333$ and $10 / 134,159$, respectively. Thus, they observed a 5.4 fold increased rate with pooled-donor platelets. ${ }^{16}$ In an AABB Educational Session in Transfusion Medicine, Hillyer et al. reported that the prevalence of the bacterial contamination of whole blood derived platelets was 33.9 per 100,000 units compared to apheresis platelets whose prevalence was 51.0 per 100,000 units. ${ }^{15,17}$

The effect of bacterial screening of apheresis platelets has been evaluated. Eder et al. pointed out that while septic reactions associated with platelet transfusion were estimated to occur in about 1:25,000 transfusions, the rate of contaminated platelets determined after implementation of detection techniques was about 1:2,000 to $1: 3,000$. The authors hypothesized that low-level contamination was not necessarily associated with a clear clinical response, and that more particularly, neutropenic and febrile patients were often under antibiotic therapy that may change the clinical picture. $^{18}$ 


\section{Platelet transfusion-related bacterial infection}

The occurrence of a severe bacterial infection related to platelet transfusion has been correlated to bacterial proliferation in platelet concentrates, and a bacterial contamination $>10^{5} \mathrm{CFU} / \mathrm{mL}$ has been considered as a serious infectious risk. ${ }^{13}$ In 2006, Yomtovian et al. reported data from a surveillance program for detection of bacterial contamination of platelets in a university hospital from 1991 to 2004. ${ }^{5}$ These data concern passive surveillance (transfusion reaction-triggered) and active surveillance (prospective methods). During the surveillance period, 216,283 platelet units were transfused. Only one type of bacterial contamination was detected by the passive surveillance method (Pseudomonas aeruginosa, 3-day old random-donor platelets). Thirty-eight contaminated platelet units or pools were detected by active surveillance. Six of them were not transfused. When transfused, the same contaminant was isolated from blood cultures obtained from the recipient in 7 cases. Coagulase-negative staphylococci was the most frequently isolated bacteria species followed by Staphyloccocus aureus. Thirteen of the patients who received the 32 contaminated platelets (31 detected by active surveillance and one detected by passive surveillance) developed transfusion reactions. Transfusion reaction rate was significantly higher for pooled random-donor platelets. Severe transfusion reactions occurred in 9 cases, and 3 patients died of complications, likely to be associated with the transfusion of contaminated platelet units (Pseudomonas aeruginosa, Staphylococcus aureus and Serratia marcescens). Nine of the 13 transfusion-reactions were associated with bacterial counts $>10^{6}$ $\mathrm{CFU} / \mathrm{mL}$. The virulence of the bacteria appeared to be more important then the bacterial load. However, transfusion reactions with fever, rigors and hypotension were observed with coagulase-negative staphylococci at bacterial counts as low as $10^{2} \mathrm{CFU} / \mathrm{mL}^{5}$

As bacterial growth increased over time, platelet units, were older, the risk of high bacterial amounts was higher, and consequently there was a higher risk of sepsis. In 1984, the FDA allowed the extension of platelet storage from five to seven days. This decision led to an increased rate of platelet transfusion-related infections, directly associated with the oldest transfused units. Therefore, in 1986, the storage was reduced from seven to five days. ${ }^{5,19}$

As mentioned above, severity of the clinical manifestations related to contaminated platelet units are determined by quantitative/ qualitative parameters (number of $\mathrm{CFU}$ infused, type of bacteria, rate of proliferation, latency phase). Whereas in some cases fever and chills are present during the transfusion, in many cases the patient remains asymptomatic. In the symptomatic recipient, fever and chills may be observed within two hours after the start of transfusions. Hypotension, nausea, vomiting, diarrhea, oliguria, respiratory symptoms and shock may be observed. The severity of a septic transfusion reaction also depends on the patient's characteristics and may be more severe in immunocompromised

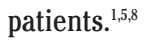

In order to reduce the risk of post-transfusion sepsis from bacterial contaminated platelets, various procedures have been implemented: improved donor selection, singledonor apheresis platelets, reduction of the contamination risk of the phlebotomy process by optimal skin disinfection procedures and the removal of the first $10-30 \mathrm{~mL}$ of the initial collected blood, storage time limitation, bacterial detection and inactivation methods. ${ }^{1,3,7}$ Indeed, as the major cause of platelet contamination is the normal skin flora at the site of punction ${ }^{3,7}$ optimal skin disinfection may significantly reduce contamination. However, when the collection needle enters the skin, bacteria may be introduced into blood. Different studies have suggested that the removal of the first aliquot of the initial collected blood may reduce the risk of bacterial contamination in blood donation. ${ }^{1,20,21}$

\section{Methods for detection of bacterial contamination of platelets: culture methods}

When compared with bacterial detection methods, surrogate tests such as $\mathrm{pH}$ measurement, glucose level determination or Gram's stain coloration have been shown to have low sensitivity and thus, can not be recommended. ${ }^{1}$ Two methods have been approved by the FDA for the detection of bacterial contamination in platelets. The first one is BacT/ALERT $^{\circledR}$ (BioMérieux Inc.), an automated colorimetric blood culture method, based on the detection of carbon dioxide produced by proliferating microorganisms, which allows the detection of both aerobic and anaerobic bacteria as well as yeasts and fungus. ${ }^{4,8,10}$ The second one is eBDS $^{\circledast}$ (Pall Corporation), an enhanced bacterial detection method based on the measurements of oxygen consumption by bacteria in the milieu. ${ }^{4,14}$ A comparison between the advantages and disadvantages of both methods is presented in Table 1 [adapted from (4)]. The Verax Biomedical Platelet PGD ${ }^{\circledR}$ Test for Bacterial detection (Verax Biomedical, Inc.) is a new rapid and qualitative immunoassay test for the detection of aerobic and anaerobic bac- teria in leukocyte reduced apheresis platelets. However, in the absence of sufficient data, a comparison between this method and both BacT/ALERT $^{\circledR}$ and Pall eBDS ${ }^{\circledR}$ is not possible.

BacT/ALERT $^{\circledR}$ is an automated colorimetric blood culture method allowing the detection of both aerobic and anaerobic bacteria as well as yeasts and fungal microorganisms, in two culture bottles, one for aerobic and one for anaerobic pathogens. The bottom of the bottles contains a pH sensitive liquid sensor which changes its color according to the amounts of $\mathrm{CO}_{2}$ released. Whereas bacteria produce $\mathrm{CO}_{2}$, yeasts and fungi are high acid-producing organisms. Inoculation of approximately 7.5 $\mathrm{mL}$ of the platelet sample is necessary for each bottle, and is performed 24 hours after collection. The bottles are then incubated at $37^{\circ} \mathrm{C}$. The $\mathrm{CO}_{2}$ production is correlated with the alteration of the reflection of the light on the sensor. When the color changes, an alarm is set off. The bottles are continuously analyzed and tested for up to 5-7 days. This system has been used for routine detection of platelet bacterial contamination in the Netherlands, Belgium and Wales for several years. ${ }^{4,8,10}$

In 2002, McDonald et al. reported data resulting from the evaluation of the BacT/ALERT $^{\circledR}$ system after inoculation, in 2day old apheresis platelets, of different bacterial species ( 9 gram positive, 5 gram negative) and one fungal microorganism at a concentration of $10-100 \mathrm{CFU} / \mathrm{mL}$. The results were compared to thioglycollate broth cultures. The mean time for the bacterial detection ranged between 9.1-48.1 hours, with the exception of Propionibacterium acnes (89-177.6 hours). ${ }^{22}$ Analogous results were obtained by Brecher $e t$ $a l .{ }^{19}$ who also confirmed the large delay required for detection of Propionibacterium acnes. However, it is important to note that anaerobic Propionibacterium acnes has a poor growth in the aerobic platelet conditions, and that its clinical relevance is all but clear., ${ }^{2,19,22}$ As bacterial load may be very low in freshly collected platelets $(<10 \mathrm{CFU} / \mathrm{mL}$ sometimes even $<1 \mathrm{CFU} / \mathrm{mL})^{10}$ a storage period $\geq 24$ hours is required before inoculation,,${ }^{10,19,22}$ in order to allow bacterial growth and to avoid false negative results.

To better assess the prevalence and nature of bacterial contamination of pooled and apheresis platelets, the GERMS (German Evaluation of Regular Monitoring Study) Group of the Red Cross Transfusion Services initiated a prospective multimember study including 9 different centers. The results of this study have been reported by Schrezenmeier et al. in 2007. The BacT/ALERT ${ }^{\circledR}$ method was used to analyze 52,243 platelet concentrates $(15,198$ collected by apheresis and 37,045 pooled platelets). Of the 282 platelet concentrates with a first positive culture, a 
Table 1. A comparison of the advantages and disadvantages of BacT/ALERT ${ }^{\circledR}$ and Pall eBDS $^{\circledR}$, according to the data reported by Schmidt et al. ${ }^{4}$ The sensitivity, efficiency and manageability of BacT/ALERT ${ }^{\circledR}$ and Pall eBDS $^{\circledR}$ were compared in a multicenter-study carried out in 4 German centers. It concerned 6,307 pooled platelets and 4,730 apheresis.

\begin{tabular}{lll}
\multicolumn{1}{l}{ Pall eBDS } & BacT/ALRT $^{\odot}$ \\
Advantages & Sensitivity* & Sensitivity* \\
& Good specificity** & Detection of aerobic and anaerobic bacteria, yeasts, and fungal microorganisms \\
\hline & Closed system & The bottles are continuously analyzed and tested, for up to 5-7 days \\
& Easy and quick handling & Easy and quick handling \\
\hline Disadvantages & $\begin{array}{l}\text { Detection of aerobic and only facultative } \\
\text { anaerobic bacteria }\end{array}$ & Specificity* \\
& $\begin{array}{l}\text { A punctual measure in time whereas platelets } \\
\text { may be transfused until 5 days after collection }\end{array}$ & Open system \\
\hline & $\begin{array}{l}\text { Platelets may be released before the time } \\
\text { of detection }\end{array}$ & \\
\hline
\end{tabular}

*This evaluation revealed a better sensitivity for the BacT/ALERT ${ }^{\circledast}$ system, identifying 4 positive samples that were missed with the Pall eBDS ${ }^{\varpi *}$ * The specificity of BacT/ALERT ${ }^{\circledast}$ (0.25\%, 28 out of 11,037 tested samples) was significantly lower compared to Pall eBDS ${ }^{\circledast}$ (0.03\%, 3 out of 11,037 tested samples).

bacteria was identified in 135 . Among these 135 concentrates, 37 were confirmed positive by second cultures. There was no significant difference in the rate of confirmed positive platelet concentrates between apheresis and pooled platelets. Among these 37 confirmed positive platelet concentrates, most bacteria isolated were skin flora bacteria. Propionibacterium acnes was found in $54 \%$ of them, and staphylococci species in $43 \%$ of them, with Staphylococcus epidermidis in most of the cases. Serratia marcescens and Staphylococcus aureus, which are potentially pathogenic bacteria, were isolated respectively in one plasma pooled platelet concentrate and in one apheresis platelet concentrate. This study demonstrated that a large scale routine screening of platelets prepared by different blood centers was feasible. However, the authors observed that such a screening did not allow the prevention of the transfusion of contaminated units because of the interval of time needed after inoculation and the detection of the contaminant. In addition, the risk of false negative results was not eliminated by this approach. Two cases of life-threatening sepsis due to Bacillus cereus contamination despite the BacT/ALERT $^{\circledR}$ detection method were described by te Boekhorst et al. in the Netherlands. ${ }^{15}$

In another important multi-center German study, comparing three bacterial detection methods under routine conditions, Schmidt et al. reported 2 severe transfusion reactions after transfusion of 2 split apheresis platelet concentrates contaminated with Klebsiella pneumoniae, despite a negative screening with both BacT/ALERT ${ }^{\circledR}$ and Pall eBDS $^{\circledR}$ detection methods. ${ }^{4}$

In the Netherlands, te Boekhorst et al. reported their experience with the BacT/ALERT $^{\circledast}$ system implemented in their center for routine bacterial screening of platelets in October 2001. Over a period of two years, 28,104 pooled platelets were screened: 203 of them were detected as being contaminated and 125 out of 203 had already been released at the time of the detection. Ninety percent of them were already transfused. No adverse reactions such as fever, hypotension, or other unexplained clinical deterioration, were observed after a contaminated transfusion. Early detection ( $\leq 48$ hours) of bacterial contamination with microbiological confirmation was possible in 59 concentrates, and 48 of them could be recalled. For late detection ( $>48$ hours), only 33 of 125 contaminated concentrates could be recalled. The authors also observed that $68 \%$ of the BacT/ALERT ${ }^{\circledR}$ screening cultures became positive after an incubation of 48 hours. ${ }^{15}$ They noted that this low rate was in contrast with several studies that showed higher rates of bacterial detection after an incubation of 48 hours. For instance, Wagner and Robinette showed that deliberate bacterial inoculation in platelet concentrates could be detected after 48 hours in all of the cases. ${ }^{15,23}$ Brecher et al. reported detection of inoculated microorganisms in apheresis platelet units (with the exception of Propionibacterium acnes) in a mean time of 9.3-18.9 hours (10 CFU/mL) or 8.7-18.2 hours (100 CFU/mL). ${ }^{15,24}$ Te Boekhorst et al. pointed out the fact that this difference could be explained by a presumably very low bacterial load in their platelet concentrates compared to the experimental inoculation load. ${ }^{15}$

As previously mentioned, Pall eBDS ${ }^{\circledast}$ is a culture method system based on the bacterial consumption of oxygen and only allows detection of aerobic and facultative anaerobic bacteria. Twenty-four hours after collection, $3 \mathrm{~mL}$ of the platelet concentrate are filtered in order to remove platelets and leukocytes, and then are inoculated into a sampling bag. The pouch contains two tablets: i) a sodium polyanethol sulphonate dissolvable tablet that reduces the natural inhibitors of bacterial growth and also acts as a platelet aggregating agent in order to lower platelet competitive consumption of $\mathrm{O}_{2}$ and, ii) a trypticase soy medium-containing tablet that enhances the sensitivity by providing nutrients for bacterial growth. The sample is incubated for 24 hours at $35^{\circ} \mathrm{C}$, and the level of $\mathrm{O}_{2}$ is measured. ${ }^{2,4,10,14}$

Like BacT/ALERT $^{\circledast}$, the Pall eBDS $^{\circledR}$ in vitro sensitivity was determined to be between 1-10 $\mathrm{CFU} / \mathrm{mL}$. Moreover, in order to reduce the risk of false negative results, a period of storage $\geq 24$ hours has been advocated. ${ }^{10}$ The performance of the Pall eBDS ${ }^{\circledR}$ was evaluated in four test sites after inoculation 1-15 CFU/mL of 10 different bacterial species known to be associated with fatal platelet transfusion related outcome. The inoculated samples were transferred in Pall eBDS ${ }^{\circledR}$ bags immediately after inoculation or after a 24 hour storage at $22^{\circ} \mathrm{C}$. The results were reported by Holme $e t$ al. who showed that all samples incubated 24 hours after inoculation were detected as being contaminated (100\% sensitivity) and no false positives were obtained with 713 uninoculated platelets. $^{2}$

Fournier-Wirth et al. reported the results from a study performed in 3 transfusion centers in France on pooled and apheresis platelets. The aim of this study was to evaluate the ability of the Pall eBDS ${ }^{\circledR}$ system to detect bacterial contamination after a reduction of the incubation time. The results were compared with the BacT/ALERT ${ }^{\circledast}$ system, considered in this study as a reference. Low levels (5$50 \mathrm{CFU} / \mathrm{mL}$ ) of 5 different strains of bacteria were inoculated in the platelet units. The platelets were stored at $22^{\circ} \mathrm{C}, 24$ hours before 
sampling. Time to detection ranged between 817 hours. Sixty-three contaminated bags were incubated for 18 and 24 hours at $35^{\circ} \mathrm{C}$. Sixtyone out of $63(96.82 \%)$ were detected as being positive after 18 hours and all at 24 hours. The $\mathrm{O}_{2}$ level of the 2 samples negative at 18 hours (contaminated with Bacillus cereus) was near the detection threshold. However, the negative samples detected an $0^{2}$ level $>17 \%$. There were no false positive results (100\% specificity). They conclude that the Pall eBDS ${ }^{\circledast}$ method allows testing of platelet concentrates 42 hours after collection similarly to the Bac/T ALERT ${ }^{\circledR}$ system. ${ }^{14}$

The limitation of the Pall eBDS $^{\circledR}$ detection system concerns the failure to detect anaerobic bacteria. However, anaerobic organisms are only rarely associated with fatal infection after platelet transfusions. ${ }^{2,10,14}$

The sensitivity, efficiency and manageability of BacT/ALERT ${ }^{\circledast}$ and Pall eBDS ${ }^{\circledR}$ were compared in a multi-center study carried out in 4 German centers. ${ }^{4}$ It concerned 6,307 pooled platelets and 4,730 apheresis platelets. A microbiological reference laboratory evaluated all initially positive results. This evaluation revealed a better sensitivity for the BacT/ALERT $^{\circledR}$ system, identifying 4 positive samples that were missed with the Pall eBDS ${ }^{\circledR}$. However, the enhanced sensitivity of the BacT/ALERT $^{\circledR}$ system was offset by a reduced specificity which was defined in this study as the number of false-positive test samples. The specificity of BacT/ALERT ${ }^{\circledast}(0.25 \%, 28$ out of 11,037 tested samples) was significantly lower compared to Pall eBDS ${ }^{\circledR}(0.03 \%, 3$ out of 11,037 tested samples). However, the authors concluded that this reduced specificity might be acceptable. BacT/ALERT $^{\circledR}$ detected 32 positive samples with microbiological confirmation out of 11,037 and Pall eBDS ${ }^{\circledR}$ detected one positive sample. These samples were considered as initially positive. However, these initially positive results were not confirmed by the analysis of a second sample, either from the satellite bag, or from the original platelet bag, or from a related erythrocyte bag (in case of pooled platelet). A possible explanation may be an exogenous contamination during the test procedure. For that reason, Pall eBDS ${ }^{\circledast}$ which is a closed system may be preferable to BacT/ALERT $^{\circledR}$ which is an open one.

\section{Detection of bacterial contamination with molecular based methods}

In order to provide more rapid, sensitive and highly specific results, molecular technologies, based on the detection of ribosomal RNA of a wide variety of bacteria in a platelet contami- nated sample containing 1-10 CFU/mL, have also been evaluated. ${ }^{10,25}$

In 1999, Chaney et al. described a new process allowing the targeting of bacterial ribosomal RNA in five steps: i) cell lyses leading to the release of ribosomal RNA, ii) hybridization of bacterial ribosomal RNA with biotin and ruthenium-labeled oligonucleotide probe pairs, iii) capture of the labeled ribosomal RNA with streptavidin-coated magnetic beads, and then iv) setting of the RNA on an electrode surface and detection of ruthenium-labeled ribosomal RNA by application of voltage, v) followed by the generation of an electrochemiluminescent signal. By this approach, the authors were able to obtain a linear relationship between the electrochemiluminescent signal representing the ribosomal RNA level with the number of CFU/mL. ${ }^{26,27}$ However, even if this method appeared to be suitable for routine application, its sensitivity was not sufficient. It only allowed the detection of approximately $10^{5} \mathrm{CFU} / \mathrm{mL}^{27}$

Störmer et al. recently published the results of a study evaluating bacterial spreading in the different blood components infected by inoculation of Klebsiella pneumoniae and Staphylococcus epidermidis. Using RT-PCR, Klebsiella pneumoniae was detected in platelet concentrates immediately after its preparation. Staphylococcus epidermidis, which has a slower growth, was only detected 24 hours after the whole separation process. The authors concluded that a 24 hour storage was necessary before processing to RT-PCR. ${ }^{17}$

Even if molecular based technologies represent a high potential for bacterial detection, their applicability in the context of detection of bacteria in platelet concentrates has not yet been demonstrated.

Furthermore, their use is limited by the cost, complexity of use and, more critically, by the availability of bacterial-derived nucleic acid amplification reagents. ${ }^{25}$

In a review of the literature published in 2004 about how to improve the bacteriological safety of platelet transfusions, Blajchman et al, pointed out that all bacterial contaminants cannot currently be detected by molecular methods and that it is not clear if bacterial DNA or rRNA is the most appropriate test marker. ${ }^{28}$

One of the most important practical problems with the use of broad-range PCR is the contamination of the assay by exogenous bacterial DNA of the nucleotide amplification reagents, particularly of the bacterial derived enzymes and the bacterial DNA sequences commonly found in human blood. Moreover, the detection of a minor amount of bacterial DNA among a high quantity of human DNA may also constitute a problem. ${ }^{25}$ To our knowledge, methods based on bacterial amplification techniques are not currently employed in routine screening of platelet concentrates.

\section{Pathogen inactivation}

Pathogen reduction technologies allow inactivation of viruses and bacteria in contaminated platelet concentrates. Two main different approaches have been described.

\section{Psoralen based method}

The INTERCEPT blood system $^{\circledast}$ (Cerus Corporation) uses amotosalen which is a synthetic psoralen, an organic compound found in fruit and vegetables like limes and celery. ${ }^{29}$ Amotosalen compound has the potential to penetrate into cells, to cross the nuclear membrane, and to reversibly intercalate into helical regions of nucleic acid. Exposure to a longwave-length ultraviolet light (UVA, 320-400 $\mathrm{nm}$ ) leads to covalent crosslinks between amotosalen molecules and pyrimidine bases, blocking DNA and RNA replication (cells and pathogens with nucleic acid genomes). After light treatment, the residual amotosalen as well as its metabolites are removed by a compound adsorbing device during a prolonged incubation. Platelets do not have nuclei and are not affected by psoralens. ${ }^{29.35}$ In 2005 , Lin $e t$ al. reported results that advocate the efficiency of such an approach for virus inactivation. The authors studied 10 different families of viruses including: i) the most relevant for blood transfusion like HIV-1, HIV-2, HBV, HTLV-1, HTLV-2 or CMV, ii) viruses of emerging interest like parvovirus B19, West Nile virus, severe acute respiratory syndromehuman coronavirus, and vaccinia virus, and, iii) model viruses like duck hepatitis virus (an HBV model), bovine viral diarrhea virus (an HCV model), bluetongue virus, feline conjunctivitis virus, simian adenovirus 15 and porcine parvovirus. According to the FDA, the process was defined as being effective if the pathogen load was reduced by $6-10$ logs. The results of this study showed a significant log reduction of enveloped viruses that were uniformly sensitive to inactivation. The non-enveloped viruses showed a variable sensitivity to inactivation. Parvovirus B19 and human adenovirus 5 were inactivated to the limit of detection, whereas the other non-enveloped viruses were resistant to inactivation. ${ }^{31}$ In 2006, Singh et al. reported that the photochemical treatment of plasma with amotosalen inactivates high levels of gram positive (Streptococcus epidermidis) and gram negative (Klebisella pneumoniae, Yersinia enterocolitica) bacterias. They determined that the mean log reductions achieved were $>7.3$ for Streptococcus epidermidis and Yersinia enterocolitica and $>7.4$ for Klebisella pneumoniae. Photochemical treatment was also efficient at high initial titers on spirochetes with mean-reductions $>5.9$ for Treponema pallidum and $>10.6$ for Borrelia burgdorferi and on protozoa with mean-reduc- 
tion $>6.9$ for Plasmodium falciparum, $>5$ for Trypanosomia cruzi and $>5.3$ for Bancrofti microti. They also showed the maintenance of clotting time and plasma coagulation factor activity after photochemical treatment. ${ }^{35,36}$ Genomic DNA in leukocytes is modified by psoralens that are able to inactivate more than 5.4 logs of T lymphocytes and to disrupt more base pairs (1:83) than gamma-irradiation $(1: 37,000) \cdot{ }^{35}$ Grass et al. reported that a dose of $0.05 \mu \mathrm{mol} / \mathrm{L}$ of amotosalen, which is 3,000 fold lower than the dose used for viruses and bacteria inactivation, was sufficient to inactivate $\mathrm{T}$ lymphocytes after $1 \mathrm{~J} / \mathrm{cm}^{2}$ of UVA illumination. ${ }^{33}$ The extreme sensitivity of the T lymphocytes to psoralens suggests that this treatment has the potential to reduce the incidence of leukocyte mediated adverse immune reactions associated with platelet transfusion like transfusion associated graft-versus-host disease and platelet related febrile non-hemolytic transfusion reaction. ${ }^{12,33,37}$ Platelet concentrates treated with psoralens seem to have a comparable in vitro function compared with nontreated platelet concentrates and their viability seem to be conserved..$^{32,38-40}$

In 2004, McCullough et al. reported the results of the SPRINT trial which was a prospective, randomized, controlled, doubleblind parallel group phase III study carried out to evaluate the efficacy and the safety of photochemical treated with amotosalen platelets compared with non-treated control platelets collected by apheresis. The efficacy was defined by prevention and treatment of significant bleeding: proportion of patients with WHO grade 2 bleeding as primary efficacy end point, the proportion with WHO grade $3-4$ bleeding, number of days of WHO grade 2 bleeding, one hour and 24 hour platelet count increments, corrected count increments, number of days to next platelet transfusion, number of platelet transfusion incidence of platelet refractoriness and number of erythrocyte concentrate transfusions as secondary efficacy end points. Safety end points were defined by the number of platelet transfusion reactions, development of antibody to potential amotosalen neoantigens and overall safety. The study included 671 thrombocytopenic patients needing platelet transfusion support: 318 received photochemical treated platelets, 327 control platelets and 26 of them did not require platelet transfusion. This trial showed that whereas the hemostatic effect of both photochemical treated and control platelets were comparable, the transfusion of treated platelets was associated with a lower platelet count increment after transfusion. This lower platelet count increment could partly be explained by the lower mean platelet dose in the photochemical treated group $\left(3.7 \times 10^{11} \mathrm{vs}\right.$. $4 \times 10^{11}$ in the control group; $p<0.01$ ) and by a greater proportion of treated platelet that con- tained $<3 \times 10^{11}$ platelets. Thus, patients who received photochemical treated platelets received more platelet transfusions and had a shorter interval between transfusion than patients who received conventional platelets. ${ }^{41}$

Studies performed in animals and humans reported no evidence for a toxicity of psoralen treatment. ${ }^{34,40,42}$ Webert et al. related acute toxicity with amotosalen after UVA activation in rats with a lethal threshold dose of $150 \mathrm{mg} / \mathrm{kg}$. In dogs, central nervous system alterations were observed after a threshold dose of $30 \mathrm{mg} / \mathrm{kg}$. These doses were respectively 150,000 and 30,000 fold higher than the dose used for pathogen inactivation. Reproductive toxicity, determined by histological rather than functional evaluation, was observed at a threshold of $0.35 \mathrm{mg} / \mathrm{kg}$, which was 350 times higher than the dose used for pathogen inactivation. Moreover, all substances used for pathogen inactivation are water soluble and rapidly excreted avoiding the bioaccumulation of trace amounts in treated blood products. ${ }^{35}$ In addition, transfusion of platelets or plasma treated with this method did not appear to induce adverse immunological response when evaluated by searching the presence of neoantigens..$^{29,35,41}$

In 2005, Lin et al. evaluated the potential of photochemical treatment with amotosalen to create neoantigens. They quantified the amounts of residual amotosalen and photoproducts in photochemical treated platelets and plasma. Patients' serum samples from 7 Phase III clinical trials including 523 patients who received more than 8,000 units of treated platelets or plasma, were assayed by enzyme linked immunsorbent assay (ELISA) for antibodies to amotosalen neoantigens. The results indicated that no neonatigens were detected by ELISA after photochemical treatment with amotosalen. ${ }^{29}$

\section{Riboflavin based method}

The Mirasol ${ }^{\circledast}$ PRT (Navigant Biotechnologies Inc.) system is similar to the psoralenbased method, but uses a different photo-sensitizer, riboflavin (vitamin B2) instead of psoralen. Riboflavin is a natural component found in food (milk, beer, eggs, yeasts, leafy vegetables), and is classified as a "GenerallyRegarded-As-Safe" compound by the FDA. . $^{30,43,44}$ Riboflavin interacts with nucleic acids after exposure to UV light (280-360 nm) and causes irreversible damage to DNA/RNA (direct electron transfer, production of singlet oxygen and production of hydrogen peroxide leading to the formation of hydroxyl radicals). A compound adsorbing device removal process for residual riboflavine metabolites may not be necessary. ${ }^{30,43}$ Perez-Pujol et al. have studied the impact of this method on the functional and biochemical characteristics of platelet concentrates. They observed, with flow cytometry studies, the same changes in treated and nontreated platelets, without modification of FvW, fibrinogen and FVa levels after five days of storage. They also showed that treated platelets have adhesive and cohesive functions similar to non-treated platelets..$^{45}$ Ruane $e t$ al. have shown that the Mirasol ${ }^{\circledR}$ PRT system is able to inactivate viruses and bacteria in platelet concentrates. They observed significant log reductions for cell-associated and cellfree HIV, West Nile virus, porcine parvovirus, and for gram positive and gram negative bacteria such as Staphylococcus epidermidis or Escherichia coli. The authors noted that the platelet $\mathrm{pH}$ and the lactate production rate were, as suggested by the literature data, predictive of recoveries in 50.8-59.8\%. Therefore, they used platelet $\mathrm{pH}$ and lactate production rate as platelet quality indicators and concluded that platelet cell quality was maintained after treatment and during storage. ${ }^{46}$ Goodrich et al. reviewed Mirasol ${ }^{\circledR}$ PRT performances and confirmed that this system was able to inactivate viruses and various bacteria species such as Staphylococcus epidermidis, Staphylococcus aureus, Escherichia coli, Pseudomonas aeruginosa, Bacillus cereus, Serratia marcescens. These data suggested a significant reduction of the risk of platelet related bacteria transmission. ${ }^{16,44,47}$ Kumar et al. showed an increased genomic DNA degradation in leukocytes and bacteria after riboflavin and UV light treatment, ${ }^{48}$ also suggesting that Mirasol ${ }^{\circledR}$ PRT technology may be an alternative to gamma irradiation to prevent transfusion associated graftversus-host disease. ${ }^{43}$

In December 2007, Klein et al. reported in a consensus conference about pathogen inactivation (Toronto, March 2007) that pathogen inactivation methods should be implemented as soon as feasible and safe methods to inactivate a broad spectrum of infectious agents are available. ${ }^{12}$ The authors established a list of existing criteria and procedures that should be changed in case of implementation of pathogen inactivation such as the suppression of screening tests for: i) Treponema pallidum; ii) agents of low infectious titer and destroyed early by pathogen inactivation like West Nile virus, which is actually systematically tested in the US and Canada; iii) agents that are sensitive to pathogen inactivation for which redundant safety measures are taken (CMV, HTLV, HbsAg and those for which the methods of detection available nowadays lack specificity and sensitivity like those used to detect bacteria). Moreover, gamma irradiation of blood components performed to eliminate the risk of transfusion associated graft-versus-host disease could be eliminated. The authors conclude that an agent that is known to be adequately inactivated by these technologies should not require screening tests unless of an unusually high infectious titer. ${ }^{12}$ 


\section{Towards a change of paradigm: inactivation versus detection}

The ability of pathogen reduction technologies to inactivate a broad spectrum of organisms (virus, fungus, bacteria, parasites) is one of the most convenient answers to face the rapidly evolving epidemiological environment as well as the continuous appearance of new pathogens. Multiple different factors effectively contribute to the occurrence of emerging or re-emerging infectious agents: migration, travel, conflicts, climatic changes, demography, and numerous less trivial factors like for instance pet trade through e-business. ${ }^{6,49-52}$ The occurrence of pathogens with a strong epidemic potential, and/or with high prevalence, as well as the diversity of existing pathogens that are not systematically detected using standard screening approaches, strongly argue for the introduction of inactivation procedures rather than continuously introducing new biological tests, each being characterized by its own sensitivity and specificity.

\section{Conclusions}

The bacterial transmission still constitutes a significant problem in transfusion medicine. Because of their favorable bacterial growth conditions (storage at room temperature, biological composition) platelets are of special concern. As shown in this review, data available suggest that bacterial detection with the technology available nowadays may present a false sense of security. To our knowledge, there is no recently approved "revolutionary" bacterial detection technology that can dramatically and definitively make platelet transfusion safe. By contrast, pathogen inactivation has demonstrated its efficiency. However, long-term studies are still needed to demonstrate the safety of this approach. Newer pathogen inactivation technologies are currently under development, like CryoFacet red blood cell and platelet technology using counterflow elutriation to remove infectious agents in plasma, followed by ozonation and treatment with germicidale UV before releasing. ${ }^{35}$ Other approaches such as "glycoengineering" the platelets in order to allow their cold storage and rapid bacterial detection (at the moment of release) are under development. ${ }^{35,53}$

In summary, this review describes recent technologies that may be used to make platelet transfusion safe, with a particular emphasis on the prevention of bacterial contamination. Based on the literature review, and more particularly for people who are not directly involved in the development and/or implementation of these particular technologies (like the authors of this review), the choice between all these different approaches is very difficult.

\section{References}

1. Hillyer CD, Josephson CD, Blajchman MA, et al. Bacterial contamination of blood components: risks, strategies, and regulation: joint ASH and AABB educational session in transfusion medicine. Hematology Am Soc Hematol Educ Program 2003;57589.

2. Holme S, McAlister MB, Ortolano GA, et al. Enhancement of a culture-based bacterial detection system (eBDS) for platelet products based on measurement of oxygen consumption. Transfusion 2005;45:984-93.

3. Palavecino E, Yomtovian R. Risk and prevention of transfusion-related sepsis. Curr Opin Hematol 2003;10:434-9.

4. Schmidt M, Karakassopoulos A, Burkhart $\mathrm{J}$, et al. Comparison of three bacterial detection methods under routine conditions. Vox Sang 2007;92:15-21.

5. Yomtovian RA, Palavecino EL, Dysktra AH, et al. Evolution of surveillance methods for detection of bacterial contamination of platelets in a university hospital, 1991 through 2004. Transfusion 2006; 46:71930.

6. Alter HJ, Stramer SL, Dodd RY. Emerging infectious diseases that threaten the blood supply. Semin Hematol 2007;44:32-41.

7. Schrezenmeier H, Walther-Wenke G, Muller TH, et al. Bacterial contamination of platelet concentrates: results of a prospective multicenter study comparing pooled whole blood-derived platelets and apheresis platelets. Transfusion 2007; 47:644-52.

8. Besson Faure I. Rapid screening for bacterial contamination of blood products. J Lab Med 2006;30:91-100.

9. Ribault S, Harper K, Grave L, et al. Rapid screening method for detection of bacteria in platelet concentrates. J Clin Microbiol 2004;42:1903-8.

10. Wagner SJ. Transfusion-transmitted bacterial infection: risks, sources and interventions. Vox Sang 2004;86:157-63.

11. Easley S, Yomtovian RA, Sullivan P, Jacobs MR. Development of proficiency testing for detection of bacterial contamination of platelet products. Transfusion 2007;47: 251-5.

12. Klein HG, Anderson D, Bernardi MJ, et al. Pathogen inactivation: making decisions about new technologies. Report of a consensus conference. Transfusion 2007;47: 2338-47.

13. Morel P, Deschaseaux M, Bertrand X, et al.
[Transfusion-transmitted bacterial infection: residual risk and perspectives of prevention]. Transfus Clin Biol 2003; 10:192200.

14. Fournier-Wirth C, Deschaseaux M, Defer $\mathrm{C}$, et al. Evaluation of the enhanced bacterial detection system for screening of contaminated platelets. Transfusion 2006; 46: 220-4.

15. te Boekhorst PA, Beckers EA, Vos MC. Clinical significance of bacteriologic screening in platelet concentrates. Transfusion 2005;45:514-9.

16. Ness P, Braine H, King $K$, A et al. Singledonor platelets reduce the risk of septic platelet transfusion reactions. Transfusion 2001;41:857-61.

17. Stormer M, Cassens U, Kleesiek K, Dreier J. Detection of bacteria in platelet concentrates prepared from spiked single donations using cultural and molecular genetic methods. Transfus Med 2007;17:61-70.

18. Eder AF, Kennedy JM, Dy BA, et al. Bacterial screening of apheresis platelets and the residual risk of septic transfusion reactions: the American Red Cross experience (2004-2006). Transfusion 2007; 47: 1134-42.

19. Brecher ME, Means N, Jere CS, et al. Evaluation of an automated culture system for detecting bacterial contamination of platelets: an analysis with 15 contaminating organisms. Transfusion 2001; 41:47782.

20. Bruneau C, Perez P, Chassaigne M, et al. Efficacy of a new collection procedure for preventing bacterial contamination of whole-blood donations. Transfusion 2001; 41:74-81.

21. Wagner SJ, Robinette D, Friedman LI, Miripol J. Diversion of initial blood flow to prevent whole-blood contamination by skin surface bacteria: an in vitro model. Transfusion 2000;40:335-8.

22. McDonald CP, Rogers A, Cox M, et al. Evaluation of the 3D BacT/ALERT automated culture system for the detection of microbial contamination of platelet concentrates. Transfus Med 2002;12:303-9.

23. Wagner SJ, Robinette D. Evaluation of an automated microbiologic blood culture device for detection of bacteria in platelet components. Transfusion 1998;38:674-9.

24. Brecher ME, Hay SN, Rothenberg SJ. Evaluation of a new generation of plastic culture bottles with an automated microbial detection system for nine common contaminating organisms found in PLT components. Transfusion 2004;44:359-63.

25. Dreier J, Stormer M, Kleesiek K. Real-time polymerase chain reaction in transfusion medicine: applications for detection of bacterial contamination in blood products. Transfus Med Rev 2007;21:237-54. 
26. Chaney R, Rider J, Pamphilon D. Direct detection of bacteria in cellular blood products using bacterial ribosomal RNA-directed probes coupled to electrochemiluminescence. Transfus Med 1999;9:177-88.

27. Rider J, Newton A. Electrochemiluminescent detection of bacteria in blood components. Transfus Med 2002;12:115-23.

28. Blajchman MA, Goldman M, Baeza F. Improving the bacteriological safety of platelet transfusions. Transfus Med Rev 2004;18:11-24.

29. Lin L, Conlan MG, Tessman J, et al. Amotosalen interactions with platelet and plasma components: absence of neoantigen formation after photochemical treatment. Transfusion 2005;45:1610-20.

30. Solheim BG, Seghatchian J. Update on pathogen reduction technology for therapeutic plasma: an overview. Transfus Apher Sci 2006;35:83-90.

31. Lin L, Hanson CV, Alter $\mathrm{HJ}$, et al. Inactivation of viruses in platelet concentrates by photochemical treatment with amotosalen and long-wavelength ultraviolet light. Transfusion 2005;45:580-90.

32. Janetzko $\mathrm{K}$, Lin $\mathrm{L}$, Eichler $\mathrm{H}$, et al. Implementation of the INTERCEPT Blood System for Platelets into routine blood bank manufacturing procedures: evaluation of apheresis platelets. Vox Sang 2004; 86:239-45.

33. Grass JA, Hei DJ, Metchette $\mathrm{K}$, et al. Inactivation of leukocytes in platelet concentrates by photochemical treatment with psoralen plus UVA. Blood 1998; 91:2180-8.

34. Allain JP, Bianco C, Blajchman MA, et al. Protecting the blood supply from emerging pathogens: the role of pathogen inactivation. Transfus Med Rev 2005;19:110-26.

35. Webert KE, Cserti CM, Hannon J, et al.
Proceedings of a consensus conference: pathogen inactivation-making decisions about new technologies. Transfus Med Rev 2008;22:1-34.

36. Singh Y, Sawyer LS, Pinkoski LS, et al. Photochemical treatment of plasma with amotosalen and long-wavelength ultraviolet light inactivates pathogens while retaining coagulation function. Transfusion 2006;46:1168-77.

37. McCullough J. Pathogen inactivation: a new paradigm for blood safety. Transfusion 2007;47:2180-4.

38. Lin L, Cook DN, Wiesehahn GP, et al. Photochemical inactivation of viruses and bacteria in platelet concentrates by use of a novel psoralen and long-wavelength ultraviolet light. Transfusion 1997; 37:42335.

39. van Rhenen DJ, Vermeij J, Mayaudon V, et al. Functional characteristics of S-59 photochemically treated platelet concentrates derived from buffy coats. Vox Sang 2000; 79:206-14.

40. Pineda A, McCullough J, Benjamin RJ, et al. Pathogen inactivation of platelets with a photochemical treatment with amotosalen $\mathrm{HCl}$ and ultraviolet light: process used in the SPRINT trial. Transfusion 2006; 46:562-71.

41. McCullough J, Vesole DH, Benjamin RJ, et al. Therapeutic efficacy and safety of platelets treated with a photochemical process for pathogen inactivation: the SPRINT Trial. Blood 2004;104:1534-41.

42. McCullough J. Pathogen inactivation of platelets. Transfusion alternatives in transfusion medicine 2006;2:121-6.

43. Seghatchian J, de Sousa G. Pathogenreduction systems for blood components: the current position and future trends. Transfus Apher Sci 2006; 35:189-96.
44. Goodrich RP, Edrich RA, Li J, Seghatchian J. The Mirasol PRT system for pathogen reduction of platelets and plasma: an overview of current status and future trends. Transfus Apher Sci 2006;35:5-17.

45. Perez-Pujol S, Tonda R, Lozano M, et al. Effects of a new pathogen-reduction technology (Mirasol PRT) on functional aspects of platelet concentrates. Transfusion 2005; 45:911-9.

46. Ruane PH, Edrich R, Gampp D, et al. Photochemical inactivation of selected viruses and bacteria in platelet concentrates using riboflavin and light. Transfusion 2004;44:877-85.

47. Engelfriet CP, Reesink HW, Blajchman MA, $\mathrm{R}$ et al. Bacterial contamination of blood components. Vox Sang 2000;78:59-67.

48. Kumar V, Lockerbie 0, Keil SD, et al. Riboflavin and UV-light based pathogen reduction: extent and consequence of DNA damage at the molecular level. Photochem Photobiol 2004;80:15-21.

49. Morris JG, Potter M. Emergence of new pathogens as a function of changes in host susceptibility. Emerg Infect Dis 1997; $3: 435-41$.

50. Chomel BB, Belotto A, Meslin FX. Wildlife, exotic pets, and emerging zoonoses. Emerg Infect Dis 2007;13:6-11.

51. Marano N, Arguin PM, Pappaioanou M. Impact of globalization and animal trade on infectious disease ecology. Emerg Infect Dis 2007;13:1807-9.

52. Gayer M, Legros D, Formenty P, Connolly MA. Conflict and emerging infectious diseases. Emerg Infect Dis 2007;13:1625-31.

53. Sorensen AL, Hoffmeister KM, Wandall HH. Glycans and glycosylation of platelets: current concepts and implications for transfusion. Curr Opin Hematol 2008; 15:606-11. 